\title{
ІНТЕЛЕКТУАЛЬНА СИСТЕМА ВИЯВЛЕННЯ АНОМАЛІЙ В РЕНТГЕНІВСЬКИХ ЗНІМКАХ ІЗ ЗАСТОСУВАННЯМ МЕТОДІВ DEEP LEARNING
}

\begin{abstract}
Моделі виявлення патологічних структур за допомогою нейронних мереж (НМ), дозволяють прискорити процес діагностики захворювань і знижують частину помилок та повторних обстежень пацієнтів. У статті розглядаються проблеми $і$ методи машинної класифікації та розпізнавання рентгенівських знімків (CXR), а також питання удосконалення штучних НM, які використовуються для підвищення якості класифікаиії рентгенологічних синдромів. НМ ідеальні для розпізнавання захворювань з використанням сканувань, оскільки немає необхідності надавати конкретний алгоритм для визначення захворювання. На основі огляду останніх досліджень і публікацій сформульовані основні завдання, які необхідно вирішити при моделюванні системи. Крім того, були проаналізовані архітектури НМ. Описані їх недоліки і переваги. Встановлено, щчо сучасні методи виявлення аномалій (хвороб) в СХR мають складнощзі з недостатньою кількістю учбових даних, стандартизацію зображень $i$ з попередньою сегментацією навчального набору. Сформовані конкретні засоби розв'язання описаних проблем з якими стикаються НМ при аналізі даних. В якості рішення запропоновано використання методів глибоко навчання, а саме згорткової НМ на основі зворотного розповсюдження помилки $i$ стохастичного градієнтного спуску з попередньою сегментачією тренувальної вибірки та застосовування трансферного навчання для категоризачї хвороб на медичних зображеннях. Для реалізації поставлених завдань обрані сучасні інформаційні технології. Розроблена архітектура інтелектуальної системи має можливість розпізнавати аномалії в CXR на рівні лікарів та рентгенологів й використовує середовище глибинного навчання. Зроблено висновок, щяо незважаючи на багатообіияючі, в деяких випадках вражаючі, результати інтелектуальних систем, серйозні проблеми залишаються, особливо в тому, що стосується теоретичної основи, яка б чітко пояснила способи визначення оптимального вибору моделі, типу і структури для конкретного завдання або для глибокого розуміння причин, за якими конкретна архітектура або алгоритм ефективні в цьому завданні чи ні.

Ключові слова: глибоке навчання; згорткова нейронна мережа; методи розпізнавання образів; попередня обробка даних; рентгенограма; трансферне навчання.
\end{abstract}

А.С. ГРИЦАЙ

Приазовский государственный технический университет, г. Мариуполь ORCID: 0000-0001-6896-4269

Т.А. ЛЕВИЦКАЯ

Приазовский государственный технический университет, г. Мариуполь ORCID: 0000-0003-3359-1313

\section{ИНТЕЛЛЕКТУАЛЬНАЯ СИСТЕМА ВЫЯВЛЕНИЯ АНОМАЛИЙ В РЕНТГЕНОВСКИХ СНИМКАХ С ПРИМЕНЕНИЕМ МЕТОДОВ DEEP LEARNING}

\begin{abstract}
Модели выявления патологических структур с помощью нейронных сетей (НС), позволяют ускорить процесс диагностики заболеваний и снижают часть ошибок, а также повторных обследований пацичентов. В статье рассматриваются проблемы и методы машинной классификации и распознавания рентгеновских снимков (CXR), а также вопросы совершенствования искусственных НС, которые используются для повышения качества классификаџии рентгенологических синдромов. НС идеальны для распознавания заболеваний с использованием сканирования, поскольку нет необходимости предоставлять конкретный алгоритм для определения заболевания. На основе обзора последних исследований и публикаций сформулированы основные задачи, которые необходимо решить при моделировании системь. Кроме того, были проанализированы архитектуры НС. Описань их недостатки и преимущества. Установлено, что современные методы обнаружения аномалий (болезней) в CXR имеют сложности с недостаточным количеством учебных данных, стандартизации изображений и предварительной сегментаџией учебного набора. Сформированы конкретные способы
\end{abstract}


решения описанных проблем, с которыми сталкиваются НС при анализе данных. В качестве решения предложено использование методов глубоко обучения, а именно сверточных НС на основе обратного распространения ошибки и градиентного спуска с предварительной сегментацией тренировочной выборки и применения трансферного обучения для категоризации болезней на медицинских изображениях. Для реализации поставленных задач выбраны современные информационные технологии. Разработана архитектура интеллектуальной системы, которая имеет возможность распознавать аномалии в CXR на уровне врачей и рентгенологов используя среду глубинного обучения. Сделан вывод, что несмотря на многообещтающие результаты интеллектуальных систем, серьезные проблемы остаются, особенно в том, что касается теоретической основы, которая бы четко объяснила способы определения оптимального выбора модели, типа и структуры для конкретной задачи или для глубокого понимания причин, по которым конкретная архитектура или алгоритм эффективны в этой задаче.

Ключевые слова: глубокое обучение; сверточная нейронная сеть; методы распознавания образов; предварительная обработка данных; рентгенограмма; трансферное обучения.

A.S. HRYTSAI

Pryazovskyi state technical university, Mariupol ORCID: 0000-0001-6896-4269

T.A. LEVITSKAYA

Pryazovskyi state technical university, Mariupol ORCID: 0000-0003-3359-1313

\section{INTELLIGENT SYSTEM FOR DETECTING ANOMALIES IN X-RAY IMAGES USING DEEP LEARNING METHODS}

Models for identifying pathological structures using neural networks (NN) can accelerate the process of diagnosing diseases and reduce the proportion of errors and re-examination of patients. The article discusses the problems and methods of machine classification and recognition of X-ray images, as well as issues of improving artificial $N N$, which are used to improve the quality of classification of X-ray syndromes. $N N$ are ideal for the recognition of diseases using scanning, since there is no need to provide a specific algorithm for determining the disease. Based on a review of recent studies and publications, the main tasks are formulated that need to be solved when modeling the system. In addition, the architecture of the NN was analyzed. Their disadvantages and advantages are described. It has been established that modern methods for detecting anomalies (diseases) in radiographs have difficulties with insufficient training data, standardization of images, and preliminary segmentation of the training set. Specific ways of solving the described problems that $N N$ faced when analyzing data have been formed. As a solution, it is proposed to use deep learning methods, namely convolutional NSS based on the back propagation of error and gradient descent with preliminary segmentation of the training sample and the use of transfer training to categorize diseases in medical images. For the implementation of the tasks selected modern information technology. An intelligent system has been developed that has the ability to recognize anomalies in radiographs at the level of doctors and radiologists and uses a deep learning environment. It is concluded that despite the promising, in some cases impressive, results of intelligent systems, serious problems remain, especially with regard to the theoretical basis, which would clearly explain how to determine the optimal choice of model, type and structure for a specific task or for a deep understanding the reasons why a particular architecture or algorithm is effective in this task.

Keywords: deep learning; convolutional neural network; pattern recognition methods; preliminary data processing; roentgenogram; transfer training.

\section{Постановка проблеми}

Сьогодні тільки близько $10 \%$ населення в світі мають доступ до якісного медичного обслуговування, а більша частина світу навіть не має доступу до основних медичних послуг. В розвинутих країнах система охорони здоров'я перебуває під напругою, зі зростаючою вартістю i тривалим часом очікування. Медичні установи можуть генерувати сотні, якщо не тисячі рентгенограм (CXR) в день. У загальному випадку читання CXR $\epsilon$ досить складним завданням як для рентгенологів, так і для лікарів. Цей процес вимагає високого ступеня майстерності і концентрації. Середній час, необхідний добре навченому рентгенологу, щоб прочитати CXR, становить близько 1-2 хвилин.

Дослідження за допомогою нейронних мереж (HM) стикаються з наступними проблемами:

- кількісна оцінка невизначеності. Засновані на глибокому навчанні рішення для біомедичних застосувань можуть істотно виграти від гарантій надійності прогнозів i кількісного визначення невизначеності. Внаслідок біологічної мінливості і меж точності обладнання біомедичні дані складаються не 3 точних вимірювань, а 3 оцінок 3 шумом. Отже, вкрай важливо отримати міри невизначеності, які фіксують, як шум у вхідних значеннях поширюється через глибокі НM; 
- обмеження даних. Відсутність великомасштабних, високоякісних, правильно маркованих даних впливає на глибоке навчання майже в усіх напрямках;

- апаратні обмеження і масштабування. Ефективне масштабування глибокого навчання $\epsilon$ складним завданням. 3 навчанням НM i їх використанням для прогнозування пов'язані великі обчислювальні витрати (наприклад, час, пам'ять і енергія);

- спільне використання даних, коду і моделі. Надійна культура обміну даними, кодом і моделями прискорить прогрес в цій області. Культурні бар'єри для обміну даними, найкраще уловлюються 3 використанням визначення «дослідницький паразит» для опису вчених, що використовують дані інших дослідників. В області, яка враховує тільки відкриття, а не важку роботу по збору корисних даних, важко заохотити вчених ділитися своїми насилу завойованими даними;

- обмежена кількість даних навчання. Біомедичні набори даних часто містять обмежену кількість примірників або міток, це може призвести до низької продуктивності алгоритмів глибокого навчання. Методи навчання переносу, також відомі як адаптація домену, дозволяють переносити витягнуті шаблони між різними наборами даних і навіть доменами.

Аналіз останніх досліджень і публікацій

Ряд досліджень було проведено для діагностики захворювань грудної клітини з використанням методології штучного інтелекту. Згідно зі статтею «Можливості та перешкоди для глибокого вивчення біології і медицини» глибоке навчання може бути застосовано, щоб відповісти на фундаментальні біологічні питання. Це особливо підходить для використання великих обсягів даних 3 досліджень 3 високою пропускною здатністю [1].

Для порівняльного аналізу і класифікації рентгенологічних захворювань грудної клітини розглядається три методи: НМ зворотного поширення, конкурентна НМ і згорткова НМ [2].

Моделювання хвороб грудної клітини за допомогою НМ зворотного поширення (BPNN).

HМ зворотного розповсюдження базується на алгоритмі BPNN, вони дуже важливі і корисні при проблемах розпізнавання образів. Навчання мереж зворотного поширення включає оновлення параметрів для отримання добрих результатів класифікації. Для цього застосовується різна кількість прихованих нейронів, швидкість навчання та імпульс для отримання кращого результату класифікації. Помилки накопичені на вихідному шарі поширюються назад в мережу для коригування ваг. на рис. 1.

Архітектура спроектованої НМ зворотного поширення для зображення розміром $32 \times 32$ описана

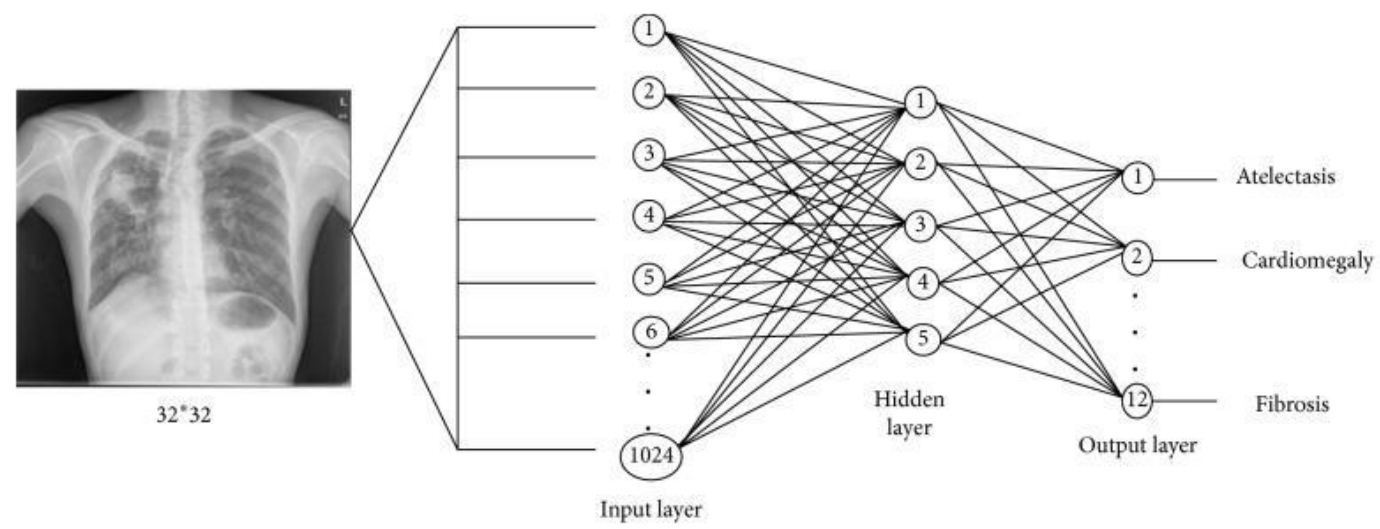

Рис. 1. Зворотне поширення НМ

Оскільки мережа зворотного поширення використовує керований алгоритм навчання, тому необхідно, щоб дані навчання були маркіровані.

Моделювання хвороб грудної клітини за допомогою конкурентної НM (CpNN).

Для класифікації захворювань грудної клітини використовується CpNN, що використовує непідтримуваний алгоритм навчання. Використовуючи той факт, що такі мережі не потребують ручного маркування даних для навчання, вони економлять час на процес маркування. Конкурентне навчання працює шляхом підвищення спеціалізації кожного вузла в мережі. Правило конкурентного навчання засноване на трьох елементах:

- набір однакових нейронів з випадково розподіленими синоптичними вагами, що приводять до різної реакції нейронів на заданий набір вхідних шаблонів;

- обмеження накладено на значення «сили» кожного нейрона;

- механізм, який дозволяє нейронам конкурувати за право реагувати на підмножину вхідних даних, влаштований таким чином, що тільки один вихідний нейрон (або тільки один нейрон у групі) $є$ активним за один раз. 
На рис. 2 показана архітектура конкурентної нейронної мережі.
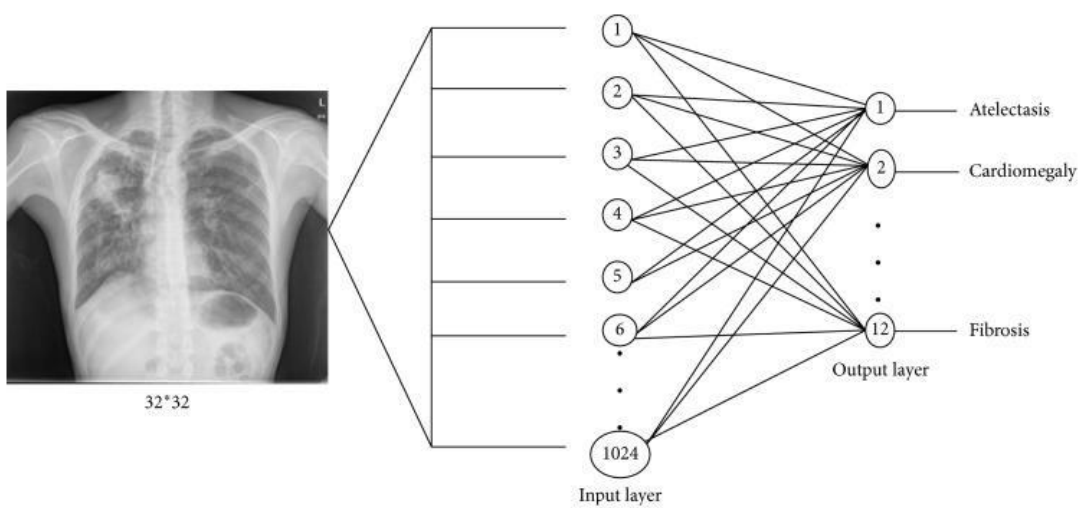

Рис. 2. Архітектура конкурентної НМ

Ці мережі використовують стратегію «переможець отримує все», коли тільки ваги, пов'язані 3 нейроном-переможцем, оновлюються в конкретну епоху, в той час як інші ваги не оновлюються. Цей процес навчання призводить до посилення кореляції між вхідними даними і відповідними нейронамипереможцями в процесі навчання.

Моделювання хвороб грудної клітини за допомогою згорткових $\mathrm{HM}(\mathrm{CNN})$.

Згорткова НМ - алгоритм глибокого навчання, який може приймати вхідне зображення, присвоювати важливість (навчальні ваги та ухили) різним аспектам / об'єктам на зображенні та мати можливість відрізняти один від іншого. Попередня обробка, необхідна для роботи мережі значно нижча порівняно з іншими алгоритмами класифікації. Хоча в примітивних методах фільтри виробляються вручну, при достатньому навчанні мережа має можливість вивчати ці фільтри/характеристики. Для ефективного навчання використовується оптимізація за допомогою стохастичного градієнтного спуску [3].

Відповідні значення параметрів навчання мережі визначаються за допомогою експериментів.

На рис. 3 показана архітектура згортової НМ.

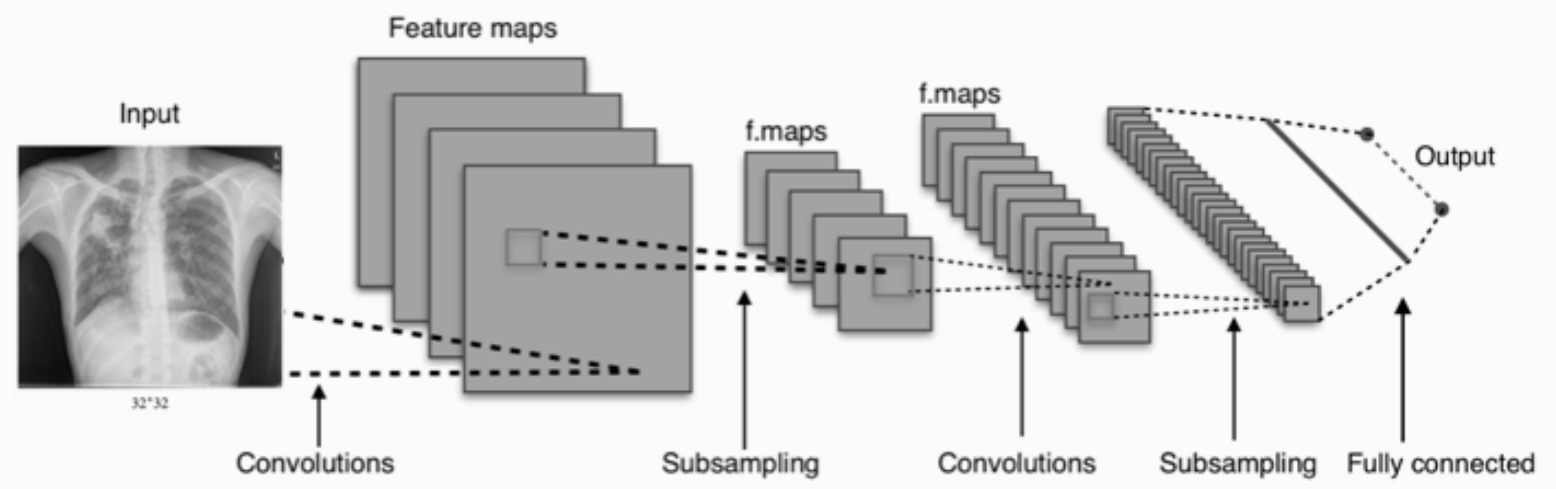

Рис. 3. Архітектура згорткової НМ

Результати порівняння роботи НМ представлені в табл. 1. Тренувальна вибірка для всіх CPNN та BPNN складалась 31000 зображень, CNN - 100000 зображень.

Таблиця 1

Порівняння роботи нейронних мереж

\begin{tabular}{|c|c|c|c|c|}
\hline Модель & $\begin{array}{c}\text { Тренувальний } \\
\text { час, с }\end{array}$ & $\begin{array}{c}\text { Відсоток } \\
\text { розпізнавання, \% }\end{array}$ & $\begin{array}{c}\text { Середньоквадратична } \\
\text { помилка }\end{array}$ & $\begin{array}{c}\text { Максимальна } \\
\text { кількість ітерацій }\end{array}$ \\
\hline BPNN & 630 & 80,04 & 0,0025 & 5000 \\
\hline CPNN & 300 & 89,57 & 0,0036 & 1000 \\
\hline CNN & 2500 & 92,4 & 0,0013 & 40000 \\
\hline
\end{tabular}

Аналізуючи табл. 1 можна зробити висновки, що CNN досягла найвищого рівня розпізнавання для навчання і тестування даних, в порівнянні з іншими використовуваними мережами. Але ця перевага CNN над іншими мережами вимагає більш тривалого часу і більшої кількості ітерацій навчання, ніж у BPNN i CpNN. Крім того, можна бачити, що три мережі досягли низької середньоквадратичної помилки 
(MSE), тоді як CNN отримала найнижчу (0,0013). Час, необхідний для сходження CNN, вище, ніж час BPNN i CpNN. Це пов'язано з глибиною структури згорткової HM, яка зазвичай потребує тривалого часу, зокрема, коли кількість входів велика. Проте, ця глибока структура є основним фактором у досягненні більш високого відсотка розпізнавання у порівнянні з іншими мережами, такими як BPNN i CpNN.

\section{Формулювання мети дослідження}

Для підвищення достовірності постановки діагнозу використовуючи рентгенівські знімки потрібна реалізація методів і алгоритмів розпізнавання образів, які відсутні в сучасних автоматизованих системах аналізу та класифікації CXR.

Основне завдання - створити ефективну архітектуру НМ для виявлення аномалій в рентгенівських знімках, розробити алгоритм навчання НМ, визначити переваги та недоліки розробленої HM.

На основі існуючих методів вирішення проблеми можна сформулювати завдання дослідження, яке полягає в застосування НМ з метою вирішення складнощів виявлення аномалій на рентгенівських знімках.

Постановка завдання:

- виявити ефективні методи попередньої обробки даних;

- розробити модель 3 використанням методів глибокого навчання, а саме за допомогою згорткової НМ для виявлення аномалій в рентгенівських знімках;

- зробити висновки та визначити ефективність НМ.

\section{Викладення основного матеріалу дослідження}

Проаналізувавши існуючі статті й дослідження були виявлені проблеми в області розпізнавання аномалій на CXR і для їх вирішення пропонуються методи і підходи описані нижче.

Метод зворотного поширення помилки. Це практика точного налаштування ваг НМ на основі частоти помилок, отриманих в попередню епоху. Правильна настройка ваг забезпечує більш низький рівень помилок, що робить модель надійної за рахунок збільшення її узагальнення. НМ поширює сигнал вхідних даних в прямому напрямку через свої параметри до моменту прийняття рішення, а потім поширює інформацію про помилку в зворотному напрямку по мережі, щоб вона могла змінювати параметри. Це відбувається крок за кроком:

- мережа робить припущення про дані, використовуючи їх параметри;

- мережа вимірюється за допомогою функції втрат;

- помилка зворотно поширюється для налаштування неправильних параметрів.

Сегментація навчальної вибірки. Виявлення часток легень є критичною стадією обробки в автоматичному аналізі CXR для легеневих розладів. Точна локалізація області легень і обробка зображень позитивно впливає на загальну продуктивність систем діагностики / виявлення, підвищує іiі точність і ефективність [4].

Поліпшення зображення легень. Вихідне зображення має низьку контрастність, і подальші методи обробки зображень можуть привести до небажаних результатів, тому є необхідним початковий крок поліпшення контрастності. Результатом цього кроку є покращене зображення, на якому область легких чітко відрізняється від фону.

Методи вирішення недостатньої кількості учбових даних. Великі медичні набори даних нелегко знайти з різних причин. Ручне анотування CXR $є$ досить трудомістким. Клінічні експерти зазвичай надають тільки невеликі набори даних. В останні роки ділитися клінічними даними стає все важче через суворі закони про конфіденційність пацієнтів.

Для того щоб вирішити проблему недостатньої кількості даних в роботі використовуються комбінація наступних методів доповнення:

- переклад. Переклад являє собою зсув щодо центру тренувального образу;

- обертання. Стратегія обертання тренувальних образів на довільну кількість градусів;

- розтягування. Анатомічні структури можуть проявлятися по-різному в різних рентгенівських зображеннях. Випадкове збільшення або зменшення масштабу може додати варіацій до таких змін;

- зрушення. Стратегія розтягування зображення в двох протилежних напрямках одночасно;

- контрастні збільшення. Медичні зображення, отримані з використанням обладнання різних виробників, можуть представляти відмінності в інтенсивності зображення.

Для того щоб отримати найкращі результати навчання НМ необхідно використовувати генератор випадковості типу i величини доповнення для кожної вибірки. Приклади застосування доповнень зображень представлені на рис. 4. 


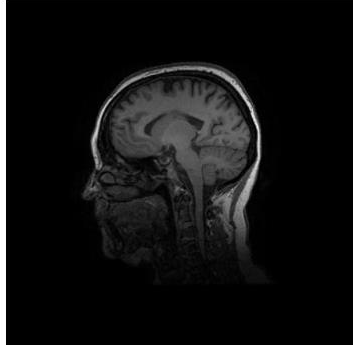

Вихідне зображення

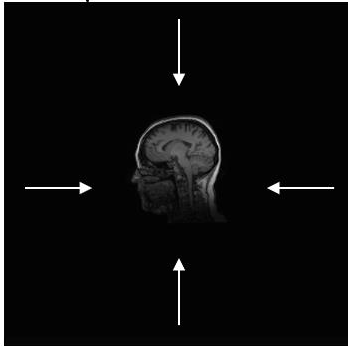

Масштабування

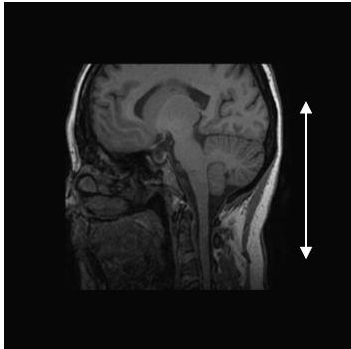

Розтягування

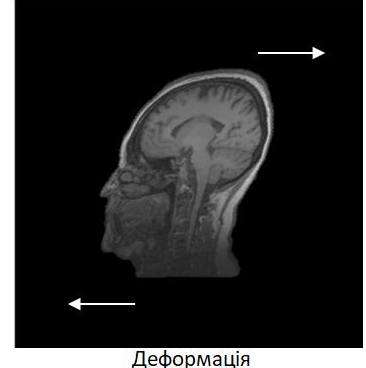

Деформація

Рис. 4. Приклади застосування доповнень до CXR

Архітектура НМ. Для побудови моделі НМ вибрана згорткова НМ.

$\mathrm{CNN}$ - це тип моделі глибокого навчання для обробки даних, що мають сіткову структуру. CNN - це математична конструкція, яка зазвичай складається 3 трьох типів шарів: згортки, об'єднання і повністю пов'язаних шарів. Перші два, шари згортки і об'єднання, виконують витяг об'єктів, тоді як третій, повністю пов'язаний шар, відображає витягнуті об'єкти в кінцевий результат, такий як класифікація.

Переваги використання CNN:

- не вимагає ручного вилучення ознак; експертами.

- архітектура CNN не обов'язково вимагає сегментації пухлин або органів людськими

Недоліки:

- CNN вимагає набагато більше даних через багату кількість доступних для оцінки параметрів і, отже, є більш дорогим в обчислювальному відношенні, що призводить до необхідності в графічних процесорах (GPU) для навчання моделі.

Як правило, для навчання НМ з нуля потрібно багато даних, але доступ до цих даних не завжди доступний. За допомогою трансферного навчання можна побудувати надійну модель машинного навчання 3 відносно невеликими даними, оскільки модель вже пройшла попередню підготовку. Крім того, час навчання скорочується, оскільки для навчання складної НМ з нуля іноді потрібні дні або навіть тижні. Трансферне навчання - це повторне використання попередньо навченої моделі для вирішення нової проблеми. Трансферне навчання має кілька переваг, але основними перевагами $є$ економія часу на навчання, підвищення продуктивності НМ і відсутність необхідності у великій кількості даних. Це дуже корисно, оскільки в більшості реальних проблем зазвичай немає мільйонів помічених точок даних для навчання складних моделей.

\section{Висновки}

В результаті були розроблені методи та підходи для розв'язання проблеми виявлення аномалій на CXR, які дозволяють розробити ефективну архітектуру HM й підвищити точність розпізнавання патологічних структур на рентгенограмах.

Глибоке навчання значно вплине на практичну реальність аналізу медичних зображень. Глибокі НМ в даний час не використовуються в клінічній практиці для медичної візуалізації, хоча деякі 3 них знаходяться в клінічних випробуваннях. Компанії починають застосовувати перші продукти, засновані на глибокому навчанні. Цей процес займе деякий час, так як попереду ще $є$ проблеми. Необхідно збільшити кількість медичних зображень для навчання моделей НМ, необхідно отримати більше досвіду 3 3D-зображеннями, а медичне співтовариство повинно стандартизувати отримання зображень.

Якщо НМ зможуть перевершити людей з розпізнавання зображень, це не означає, що лікарі залишаться без роботи. Майбутнє глибоких НМ змусить їх працювати разом з лікарями, а не змінити їх.

Незважаючи на багатообіцяючі результати, серйозні проблеми залишаються, особливо в тому, що стосується теоретичної основи, яка б чітко пояснила способи визначення оптимального вибору моделі, типу і структури для конкретного завдання або для глибокого розуміння причин, за якими конкретна архітектура або алгоритм ефективні в цьому завданні чи ні.

\section{Список використаної літератури}

1. Траверс Ч. Можливості та перешкоди для глибокого вивчення біології та медицини / Ч. Траверс. Вісник інтерфейсу королівського суспільства - 2018. - 141с.

2. Рабіх Г. Глибокі згорткові нейронні мережі для виявлення хвороб грудної клітини / Г. Рабіх. Вісник інтерфейсу королівського суспільства - 2018. - 141с.

3. Вейнховен Р.Г. Швидке тренування виявлення об'єктів із використанням стохастичного градієнтного випуску: матеріали міжнародної конференції за наявністю образу (ICPR) / Р.Г. Вейнховен - Цукуба, Японія, 2010 p - 424 с. 
4. Паттрапісетвонг П. Автоматична сегментація легких при рентгенографії грудної клітини 3 використанням теневого фільтра: матеріали конференцій IEEE / П. Паттрапісетвонг. Манчестер, Великобританія, 2016.

\section{References}

1. Travers Ching. Opportunities and obstacles for deep learning in biology and medicine, J Healthc Eng, 2018, 15(141), doi: 10.1098/rsif.2017.0387.

2. Rahib H. Abiyev, Mohammad Khaleel Sallam Ma'aitah. Deep Convolutional Neural Networks for Chest Diseases Detection, J Healthc Eng, 2018, doi: 10.1155/2018/4168538.

3. Wijnhoven R.G. Fast Training of Object Detection Using Stochastic Gradient Descent, International Conference on Pattern Recognition, 2010, doi: 10.1109/ICPR.2010.112

4. Pattrapisetwong P. Automatic lung segmentation in chest radiographs using shadow filter and multilevel thresholding, International Computer Science and Engineering Conference (ICSEC), Manchester, 2016, doi: 10.1109/ICSEC.2016.7859887. 